\title{
FACULTY TOUR OF SCANDINAVIAN CLINICS
}

Twenty members of the Faculty of Ophthalmologists, led by $\mathrm{Mr}$. W. M. Muirhead, sailed from Harwich on June 10. When they disembarked at the same port on June 28 , nearly every one had increased his girth, and all were richer in experience. No ophthalmologist could help being thrilled to see the hospitals where Rönne and Bjerrum did their work, and to stand beside Gullstrand's rocking-chair. That we should have been able, in little more than a fortnight, to visit six illustrious clinics, sail upon the Baltic, and walk in the garden of Linnaeus. 'is proof of Mr. Muirhead's genius for organisation. It was he who planned the tour, greatly to the advantage of his colleagues.

\section{Denmark}

Professor Ehlers and his assistants showed us the ophthalmic and some of the other departments of the Rijkshospitalet. After the professor had made a speech of welcome, he let us hear about some of the recent investigations pursued. Dr. Johansen described his pathological studies upon enucleated eyes, and Fru Braendstrup spoke of a method whereby the temperature of the superior fornix can be shown to exceed that of the inferior by about $0.75^{\circ} \mathrm{C}$. A refinement of technique in scotometry was the subject of Dr. HolmPedersen's paper. His three-faced test-objects - black, white and red - keep the patient "on his toes," because the object can be made to disappear (i.e., go black) anywhere on the screen. Dr. C. Edmund spoke of his preliminary research upon endogenous and exogenous factors governing the light-reflex of the cornea. Then came Mr. H. Campbell-Orr's fundus photographs and Mr. P. Jameson Evan's films showing (a) the insertion of a slip of the internal rectus into a paretic superior rectus, and (b) grafting of the outer halves of the superior and inferior recti into a paretic external rectus, together with recession of the internal rectus.

Professor Holm welcomed us to his department at the Kommunehospitalet, told us about the hospital's development, and demonstrated a number of cases. Dr. Erik Godtfredsen showed a case of naso-pharyngeal sarcoma complicated by left abducent palsy. No cervical gland metastases were found, but the diagnosis was confirmed by X-ray photographs. A case of bilateral uveo-parotid fever in a girl of 17 was also shown by Dr. Godtfredsen, who recalled with interest that Heerfordt was First Assistant in this clinic when he produced his classical description of uveo-parotitis 40 years ago. Dr. P. Braendstrup spoke about amblyopia, with special reference to its association with traumatic cataract, and he produced 
statistics showing that amblyopia is seldom acquired after childhood. A case of siderosis was demonstrated by Dr. C. J. Möllenbach.

We also attended a meeting of the Danish Ophthalmological Society at the Domus Medica under the presidency of Professor Ehlers, who proceded to confer honorary membership upon Sir Stewart Duke-Elder. Sir Stewart had also been created an Honorary Member of the Swedish Ophthalmological Society during its Annual Congress a few days previously. Papers were then delivered. Mr. R. C. Davenport spoke about glaucoma in association with high myopia, and Dr. H. Skydsgaard dealt with the problem of word-blindness. Mr. J. H. Doggart described several cases of central serous retinopathy, and Mr. C. D. Shapland produced an analysis of his results in the treatment of detached retina. Finally Dr. A. Lund described his experimental work upon the intra ocular circulation.

\section{Sweden}

Professor Larsson, who had recently returned from a visit to the United States, showed us his famous clinic in Lund, and described his researches upon lenticular metabolism by means of fluorescence estimations. He also testified to the value of anticoagulants notably dicoumarol -in the treatment of retinal venous thrombosis. Other subjects considered by Professor Larsson were the extraction of non-magnetic intra-ocular foreign bodies, and the treatment of infantile epiphora. Dr. A. E. Maumenee's film of intracapsular extraction, and Dr. R. Townley Paton's film of keratoplasty for corneal scar and for Descemetocele were shown. Dr. G. Österlind discussed the effect of milk injections upon the intra-ocular pressure, and Dr. E. Palm gave an account of his studies on the permeability of the blood-aqueous barrier to various substances, including lipoids. Mr. P. McG. Moffatt reviewed the differential diagnosis of proptosis, and stressed certain prognostic difficulties. Senile massive exudate at the macular was the subject of a talk by Mr. R. C. Davenport, who pointed out that retinitis circinata is not a clinical entity, but rather an incidental feature of certain conditions - notably senile massive exudate at the macula.

At Uppsala Professor Berg is occupied with administrative work as Rector Magnificus of the University, but he nevertheless found time to welcome us and to lead the social activities. He delegated the task of showing us the Department of Ophthalmology to the acting professor, Dr. Gunnar von Bahr, who afterwards gave a thoughtful discourse on spherical and chromatic abberration of the eye, and their effect upon human vision. Dr. U. Halldén spoke about fusional phenomena in anomalous correspondence, and the possible influence of this factor upon squint surgically treated. Dr. E. Linner discussed the work of Ascher and Goldmann on aqueous veins, and 


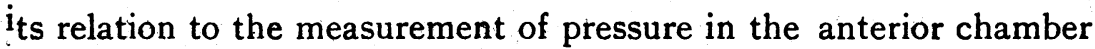
and in Schlemm's canal. Dr. K. H. Sjöström described a case of lightning-cataract, and reviewed the ocular changes arising from electric shock. An account of anterior lenticonus in a 19-year-old male was given by Dr. C. G. Åborg.

Professor G. Karpe, who has recently been appointed to the Chair of Ophthalmology at the Karolinska Institute, Stockholm, conducted us around its palatial hospital. He described his technique of electroretinography, and indicated ways in which this method of investigation can assist the prognosis, especially in cases of retinal detachment. Professor Karpe also showed some fundus photographs taken with the Nordenson camera, and we were afterwards privileged to meet Professor Nordenson himself. Dr. T. Kornerup described his investigations upon the living eye with the aid of spectrally restricted light. Various structures can be selectively displayed by green, red and other kinds of light, and he demonstrated the apparatus by which light is shattered by a prism, and the required spectral component filtered through a slit. Dr. K. O. Grandström received us at the no less palatial Södersjukhuset, and gave an account of his clinical observations upon cataract, glaucoma, arterial hypertension, intra-ocular foreign body and toxoplasmosis. Dr. W. Magnusson showed us some fine X-ray photographs.

At Göteborg, Dr. H. Rosengren spoke about his work on retinal detachment, and described his technique for injecting air into the vitreous. Afterwards he demonstrated this process on the operatingtable. Mr. Harold Ridley gave a talk on tropical ophthalmology, and emphasised the appalling havoc wrought by onchocerciasis upon Central Africans. Dr. H. Sjögren's subject was keratoconjunctivitis sicca, whose causation is not yet fully understood, though infection and endocrine dyscrasia appear to be the principal agents. Dr. S. Holm also gave a talk on Sjögren's disease.' Physiological optics was the subject of a paper by Dr. Stenström, and Dr. S. Holm underlined the importance of heredity as the main aetiological factor in refraction.

\section{Norway}

Professor Malling, who welcomed us at the Rikshospitalet, Oslo, performed two cataract extractions, and gave a talk on exfoliation of the anterior lens capsule. He maintained that, although such exfoliation is often associated with glaucoma, it is not these exfoliated particles which cause blockage of the filtration angle. Dr. M. Haarr spoke about periphlebitis as a sign of multiple sclerosis. This vascular change is ophthalmoscopically visible, he says, in the form of white infiltrates around the retinal veins anywhere except in the juxtapapillary region. Dr. O. Röe's subject was methanol-poisoning. 
He mentioned the favourable effect of sodium bicarbonate administered in the first three days, and the influence of ethyl alcohol in restricting damage from adulterated liquor. Dr. H. P. Petersen stressed the possibility of extensive colloid degeneration in the retrobulbar portion of the optic nerve, and adduced such a change as the explanation for certain cases of field-defect associated with but explained only in part by colloid bodies ophthalmoscopically visible. He suggested the simile of an iceberg, whose hidden bulk is more menacing than its exposed pinnacle.

\section{Conclusion}

Mr. Muirhead would be the first to point out that no plans, however carefully laid, can set the seal of success upon a tour. Success can only be attained by the interaction of friendly hosts and appreciative guests. Let it therefore be stated - and stated emphatically - that nobody capable of gratitude could fail to be touched by the welcome extended to us by Dane, Swede and Norwegian alike. Scandinavian hospitality is proverbial, so that we had naturally expected to enjoy those Northern lands, but the result surpassed expectation. The heads of all six clinics, together with their assistants, senior and junior, accorded us the freedom of their departments. They also flung wide open the doors of their homes, in which we passed many an hour of happy, informal talk. Kinder hostesses it is impossible to conceive, and we who were privileged to enjoy their hospitality will never forget how largely the success of the Scandinavian Tour was due to their welcome.

\section{OBITUARY}

\section{H. H. MCNABB}

We regret to record the death of Dr. H. H. McNabb, M.D., which occurred at his home at Prestbury, Cheshire, last month at the age of 74 years.

Harry Horsman McNabb was born and received his early education in Bolton, later passing on to the University of Manchester, where he qualified M.B., Ch.B. in 1898, taking the M.D. four years later. After a short period in general practice, he was appointed a resident at the Manchester Royal Eye Hospital and subsequently Assistant Honorary Surgeon', full Surgeon, Consulting Surgeon and Vice-President, his connection with the Hospital covering a period of 49 years. During most of this time he conducted an extensive 